\title{
Cardiovascular disease risk factors: Role of legislations that control marketing of breastmilk substitutes
}

\author{
Azza A.M. Abul-Fadl', Maha M. Mourad ${ }^{2}$, Oasma S. Arafa ${ }^{3}$, Hanin A. Al-Jawaldeh ${ }^{4}$ \\ From Professor, ${ }^{1}$ Department of Pediatrics, Faculty of Medicine, Benha University, ${ }^{2}$ Department of Pediatric Cardiology, Faculty of Medicine, Cairo University, \\ ${ }^{3}$ Department of Cardiology, Faculty of Medicine, Benha University, Egypt, ${ }^{4}$ Clinical Dietitian, Technical Officer, Nutrition, UNICEF Amman, Jordan
}

\begin{abstract}
Background: Cardiovascular diseases (CVDs) are the leading cause of mortality throughout the world. Breastfeeding has been shown to play a role in the prevention of CVD. The International Code for Marketing of Breastmilk Substitutes (BMSs) and its relevant resolutions (the Code) were adopted by the World Health Assembly to protect breastfeeding. Aim: This study aims to study the relationships between breastfeeding rates and laws that cover the code with CVD risk factors (obesity and blood pressure) and death from non-communicable diseases (NCDs). Methods: Data for scores given to national laws and provisions under the Code for protecting breastfeeding were obtained from the World Health Organization (WHO)/International Baby Food Action Network report in 2020. Data for exclusive breastfeeding (EBF) during infancy were obtained from United Nations International Children's Emergency Fund Global data. The WHO data for CVD risk factors in adults ( $>18$ years) included overweight, obesity raised blood pressure (RBP), raised blood glucose level (RBGL), and death from NCDs. Results: There were significant negative correlations of overweight, obesity, raised $\mathrm{BP}$, and death from NCD with $\mathrm{EBF}$ and with scores given to national laws that cover the Code. RBGL correlated negatively with overweight and obesity. Overweight, obesity, RBP, and death from NCDs correlated inversely with provisions in the national laws for monitoring and enforcement at $\mathrm{p}<0.015$. Engagement of health staff and systems and promotion in health facilities correlated with $\mathrm{RBP}$ and death from NCDs at $\mathrm{p}<0.01$. Conclusions: Prevention of CVD can benefit from improving breastfeeding rates by the enactment of national laws that cover the Code in its entirety. All countries should enact, monitor, and enforce these laws for promoting and protecting breastfeeding and preventing long-term consequences of feeding BMS.
\end{abstract}

Key words: Breastmilk substitutes, Cardiovascular disease, Hypertension, Marketing, Obesity, Protecting breastfeeding, The code

$\mathrm{C}$ ardiovascular diseases (CVDs) are the leading cause of death, among non-communicable diseases (NCDs) globally. Risk factors for CVDs include obesity, overweight, and laboratory biomarkers as high-density lipoproteins and highly sensitive C-reactive protein [1]. Worldwide, more than $70 \%$ of all deaths are due to NCDs and an estimated 41 million people are at risk of death from heart attacks, stroke, cancer, chronic respiratory diseases, diabetes, or a mental disorder. CVDs share key modifiable behavioral risk factors such as tobacco use, unhealthy diet, lack of physical activity, and the harmful use of alcohol, which, in turn, lead to overweight and obesity, raised blood pressure (RBP), and raised cholesterol, and ultimately CVDs [2]. Majority of premature deaths (82\%) occur in low- and middle-income countries and cause cumulative economic losses estimated at US\$ 7 trillion [3]. A global target has been set to reduce the overall mortality from CVDs, cancer,

\section{Access this article online}

Received - 24 June 2021

Initial Review - 13 July 2021

Accepted - 16 August 2021

DOI: $10.32677 / \mathrm{IJCH} .2021 . v 08.109 .3052$ diabetes, or chronic respiratory diseases by $25 \%$ through a Global NCD Action Plan 2013-2020 [4].

Breastmilk is a unique biological source of nutrition for infants to reach their full potential for growth and development $[5,6]$. Introduction of any kind of milk or food as replacement of breastmilk before 6 months of age can lead to many short- and longterm diseases [7]. Marketing milk formulas undermine a mother's decision to exclusively breastfeed (EBF) in the first 6 months of life and continue breastfeeding for 2 years, as recommended by international and scientific associations [8]. The International Code of Marketing of Breastmilk Substitutes (BMSs) was adopted by the World Health Assembly (WHA) in 1981 [9] and was followed by a series of relevant resolutions (the Code) to control the emerging marketing tactics for BMS [8]. Enforcement of the code, in its entirety, through national laws and monitoring implementation by reporting and taking corrective action for detected violations has been shown to improve breastfeeding rates [10].

Correspondence to: Azza A.M. Abul-Fadl, Department of Pediatrics, Faculty of Medicine, Benha University, Benha, Qaluibiya, Egypt. E-mail: abulfadl2025@ gmail.com

(C) 2021 Creative Commons Attribution-NonCommercial 4.0 International License (CC BY-NC-ND 4.0). 
Early infant feeding practices may influence the development of CVDs. Breastfeeding is associated with preventing obesity, high blood pressure, diabetes mellitus (DM), and cancer [11]. EBF seems to have a protective effect against some risk factors for CVDs in later stage of life [12-14]. In fact, in a study, breastfeeding was associated with lowering of later blood pressure [15]. Women who breastfeed are at decreased risk of developing CVDs [16]. However, there are some controversial findings that such risk factors may be associated with the reduction of CVDs [17].

This study aims to present the status of national laws that cover the Code provisions in 89 countries and some selected risk factors for CVDs such as overweight, obesity, raised blood sugar, and RBP. It also investigates the associations between the risk factors for CVDs and breastfeeding indicators for protection and promotion.

\section{METHODS}

This is a cross-sectional observational study based on the global data from national reports from various countries, validated by international organizations, and added to the global database of the World Health Organization (WHO). The country data were obtained from the WHO NCD report in 2015 [3] and included age-standardized adjusted estimates of obesity (body mass index $[\mathrm{BMI}]>30)$ and overweight $(\mathrm{BMI}>25)$; also age-standardized adjusted estimates for raised blood glucose level (RBGL) (fasting glucose $\geq 7.0 \mathrm{mmol} / \mathrm{l} ; 126 \mathrm{mg} / \mathrm{dl}$ ) or on medication for RBGL or history of diagnosis of diabetes and RBP (systolic blood pressure $\geq 140$ and/or diastolic blood pressure $\geq 90$ ) [3]. The percent deaths from NCDs were obtained from the WHO NCD report for countries in 2020 [18].

The data for the status of implementation of the national laws that cover the provisions under the Code of marketing of BMS were obtained from the most recent report for status on national implementation of the Code by the WHO and International Baby Food Action Network (IBFAN) in 2020 [19]. Data for EBF were obtained from the United Nations International Children's Emergency Fund (UNICEF) database for infant feeding practices updated to 2019 [20]. EBF is defined as babies who receive only breastmilk (medicine, vitamins, and minerals included) in the first 6 months of life ( $0-5$ months). The countries were filtered according to the availability of global data for national laws, risk factors for NCDs, and EBF data. Accordingly, 89 countries were studied and included the following based on the six WHO regions to which they are affiliated in alphabetical order included: (1) The African Region (AFR) [21]: Algeria, Benin, Botswana, Burkina Faso, Cameroon, Chad, Comoros, Côte d'Ivoire, Ethiopia, Gabon, Gambia, Ghana, Kenya, Madagascar, Malawi, Mali, Mozambique, Niger, Nigeria, Senegal, South Africa, Uganda, the United Republic of Tanzania, Zambia, and Zimbabwe; (2) the American Region (AMR)[14]: Bolivia, Brazil, Colombia, Costa Rica, Dominican Republic, Ecuador, El Salvador, Honduras, Mexico, Nicaragua, Paraguay, Peru, Trinidad and Tobago, and Uruguay; (3) the Eastern Mediterranean Region (EMR) [15]: Afghanistan, Bahrain, Egypt, Iran (Islamic Republic of), Iraq, Jordan, Kuwait, Oman, Pakistan, Saudi Arabia, Sudan, Syrian Arab Republic, Tunisia, the United
Arab Emirates, and Yemen; (4) the European Region (EUR) [22]: Azerbaijan, Bosnia and Herzegovina, Croatia, Georgia, Albania, Ireland, Italy, Kazakhstan, Kyrgyzstan, Luxembourg, the Netherlands, Norway, Republic of Moldova, Serbia, Spain, Sweden, Switzerland, Tajikistan, Turkey, Turkmenistan, the United Kingdom, and Ukraine; (5) the South East Asia Region (SEAR) [7]: Bangladesh, India, Indonesia, Maldives, Myanmar, Nepal, and Thailand; and (6) the West Pacific Region (WPR) [6]: China, Lao People's Democratic Republic, Mongolia, the Philippines and Solomon Islands, and Viet Nam.

The provisions under the national laws that cover the International Code of Marketing BMS and the subsequent relevant WHA resolutions [18] are intended to protect breastfeeding. The national laws were analyzed using a checklist of relevant provisions covered under subsequent WHA resolutions, including the guidance associated with WHA 69.9. All legal national measures were scored according to how well they reflect the recommendations put forward in the Code. Each provision of the Code was given a point value, with the total points adding up to 100 . Seven provisions underwent analysis in this study, including the following: (1) Monitoring and enforcement (10 points): This identifies who is responsible for monitoring compliance, defines sanctions for violations, and requires that monitoring and enforcement should be independent, transparent, and free from commercial influence; (2) promotion in health-care facilities (10 points): This type of prohibition explicitly includes display of products under scope, display of placards or posters concerning these products, distribution of any material provided by a manufacturer or distributer, use of health facility to host events, contests, or campaigns and use of personnel provided by or paid by manufacturers and distributers; and (3) engagement with health workers (HWs) and health systems (HSs) (15 points) by gifts or incentive that includes financial or material inducements to promote BMS as well as fellowships, study tours, research grants, attendance at professional conference (disclosure to the institution if fellowships not prohibited), provision of free or low-cost supplies in any part of the HS, donations of equipment or services, (or donations prohibited only if they refer to a proprietary product), product samples, product information, product information restricted to scientific and factual matters, and sponsorship of meetings for scientific and health professionals.

Data were represented as mean \pm standard deviation and statistics analysis was performed by ANOVA to estimate the F-ratio, post hoc tests to compare between individual groups using "Least significant difference" and Bonferroni tests. A comparison was made between EMR-WHO and other WHO regions. Pearson correlation was used for parametric data and Spearman correlation coefficient for non-parametric data was used to correlate the data for the national legal measures that cover the Code with the data on risk factors to NCDs and illustrated by scatter charts of Excel (Windows 10). $p<0.05$ was considered statistically significant. The results were analyzed and comparison was made between countries of the region for the data collected using SPSS package. 


\section{RESULTS}

Table 1 compares the mean age-standardized adjusted estimates (age $>18$ years) for overweight, obesity, RBGL, and RBP in the 89 countries by region as per the WHO classification.

Table 2 presents the distribution of countries by the presence of legal measures that are relevant to the Code relative to the number of studies included in the study.

Table 3 compares the mean score for the score given to the national law in the 89 countries by region. Post hoc analysis showed that mean scores for monitoring and enforcement were significantly higher in EMR than in EUR $(p<0.05)$ but lower than other regions $(p>0.05)$ and EUR was significantly lower than all other regions $(\mathrm{p}<0.05)$.

Table 4 presents correlative studies of EBF and the total score of national laws that cover the Code with overweight, obesity, RBP, and RBGL as risk factors of CVDs and death from NCDs in the EMR versus other regions of the WHO.

\section{DISCUSSION}

Scores for laws covering the Code were highest in countries from the SEAR and EMR. The high-income countries (HICs) mostly in EUR and AMR covered fewer provisions in their legal measures in protecting the Code, particularly for monitoring and enforcement. Protecting breastfeeding through legal enforcement of the Code and monitoring implementation using the NetCode kit developed by IBFAN, UNICEF, and the WHO is important to ensure continued compliance to the Code $[21,22]$. The WHO status report and the IBFAN in 2020 showed that 136 countries had national laws that cover the provisions required under the Code [19].

The mean age-standardized adjusted estimates of overweight were highest in the EMR, AFR, and EUR countries. Mean regional estimates of obesity were highest in EMR countries. This may be because countries with high economies in the EMR have the highest ranks and rates of obesity in the world as Saudi Arabia,

Table 1: Comparison of the mean age-standardized adjusted estimates (age $>18$ years) for overweight, obesity, raised blood glucose, RBP, and death from non-communicable diseases in 89 countries by region

\begin{tabular}{|c|c|c|c|c|c|c|c|c|}
\hline Region & AMR & AFR & EMR & EUR & SEAR & WPR & $\mathbf{F}$ & $\mathbf{p}$ \\
\hline \multicolumn{9}{|c|}{ Overweight $(\mathrm{BMI} \geq 25)$} \\
\hline $\begin{array}{l}\text { Number } \\
(\text { Mean } \pm \text { SD) }\end{array}$ & $25(30.6 \pm 10.4)$ & $14(56.09 \pm 4.8)$ & $15(56.1 \pm 18.9)$ & $22(55.9 \pm 5.2)$ & $7(22.7 \pm 5.3)$ & $6(34.7 \pm 17.1)$ & 25.2 & 0.00 \\
\hline \multicolumn{9}{|c|}{ Obesity $(\mathrm{BMI} \geq 30)$} \\
\hline $\begin{array}{l}\text { Number } \\
(\text { Mean } \pm \text { SD })\end{array}$ & $25(8.7 \pm 5.7)$ & $14(19.5 \pm 3.9)$ & $15(22.6 \pm 10.9)$ & $22(19.1 \pm 3.7)$ & $7(4.2 \pm 1.8)$ & $6(9.4 \pm 3.8)$ & 17.1 & 0.00 \\
\hline \multicolumn{9}{|c|}{$\mathrm{RBP}(\mathrm{SBP} \geq 140$ and/or $\mathrm{DBP} \geq 90)$} \\
\hline $\begin{array}{l}\text { Number } \\
(\text { Mean } \pm \text { SD) }\end{array}$ & $25(22.6 \pm 5.0)$ & $14(19.9 \pm 3.4)$ & $15(21.1 \pm 2.7)$ & $22(26.9 \pm 5.1)$ & $7(21.7 \pm 2.1)$ & $6(20.6 \pm 2.9)$ & 6.55 & 0.000 \\
\hline \multicolumn{9}{|c|}{ RBG (fasting glucose $\geq 7.0 \mathrm{mmol} / 1$ (126 mg/dl) or on medication for $\mathrm{RBG}$ ) } \\
\hline $\begin{array}{l}\text { Number } \\
(\text { Mean } \pm \text { SD) }\end{array}$ & $25(8.9 \pm 1.9)$ & $14(9.5 \pm 2.3)$ & $15(9.5 \pm 2.3)$ & $22(15.1 \pm 3.3)$ & $7(9.2 \pm 1.04)$ & $6(10.0 \pm 3.8)$ & 11.73 & 0.000 \\
\hline \multicolumn{9}{|c|}{ Death from non-communicable diseases } \\
\hline $\begin{array}{l}\text { Number } \\
(\text { Mean } \pm \text { SD) }\end{array}$ & $25(37 \pm 10.4)$ & $14(74.6 \pm 6.1)$ & $15(67.9 \pm 14.6)$ & $22(88.5 \pm 5.9)$ & $7(70.7 \pm 7.02)$ & $6(73.7 \pm 10.4)$ & 72.94 & 0.000 \\
\hline
\end{tabular}

Table 2: Distribution of countries by the presence of legal measures that are relevant to the Code relative to the number of countries included in the study

\begin{tabular}{|c|c|c|c|c|c|c|c|c|}
\hline \multirow[t]{2}{*}{ Region } & \multicolumn{2}{|c|}{$\begin{array}{l}\text { Countries with no legal } \\
\text { measures }\end{array}$} & \multicolumn{2}{|c|}{$\begin{array}{l}\text { Countries with legal measures } \\
\text { included in the study }\end{array}$} & \multicolumn{2}{|c|}{$\begin{array}{l}\text { Countries with legal } \\
\text { measures not included in the } \\
\text { study }\end{array}$} & \multicolumn{2}{|c|}{$\begin{array}{c}\text { Total number of } \\
\text { countries with known } \\
\text { status* }\end{array}$} \\
\hline & No & Percentage & No & Percentage & No & Percentage & No & Percentage \\
\hline AFR & 13 & 30.2 & 25 & 58.2 & 5 & 11.6 & 43 & 100 \\
\hline AMR & 17 & 41.5 & 14 & 34.1 & 10 & 24.4 & 41 & 100 \\
\hline EMR** & 4 & 19.1 & 15 & 71.4 & 2 & 9.5 & 21 & 100 \\
\hline EUR & 3 & 5.7 & 22 & 41.5 & 28 & 52.8 & 53 & 100 \\
\hline SEAR & 2 & 20 & 7 & 70 & 1 & 10 & 10 & 100 \\
\hline WPR & 14 & 58.3 & 6 & 25 & 4 & 16.7 & 24 & 100 \\
\hline Total & 53 & 27.6 & 89 & 46.4 & 50 & 26.0 & 192 & 100 \\
\hline
\end{tabular}

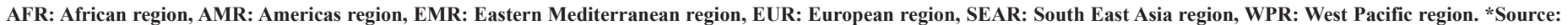
WHO/IBFAN, 2020. **State of Palestine has legal measures but not included in the global report. IBFAN: International Baby Food Action Network 
Table 3: Comparison of the mean score given to the national laws covering the Code of marketing BMS and its provisions in the 89 countries by region

\begin{tabular}{|c|c|c|c|c|c|c|c|c|}
\hline Region & AMR & AFR & EMR & EUR & SEAR & WPR & $\mathbf{F}$ & $\mathbf{P}$ \\
\hline \multicolumn{9}{|c|}{ EBF (0-5 months) } \\
\hline $\begin{array}{l}\text { Number } \\
(\text { Mean } \pm \text { SD) }\end{array}$ & $24(31.5 \pm 16.0)$ & $14(35.9 \pm 19.9)$ & $14(44.7 \pm 17.7)$ & $22(34.1 \pm 17.1)$ & $7(36.6 \pm 19.8)$ & $6(29.8 \pm 26.4)$ & 1.09 & 0.4 \\
\hline \multicolumn{9}{|c|}{ Total score given to national law $($ score $=100)$} \\
\hline $\begin{array}{l}\text { Number } \\
(\text { Mean } \pm \text { SD })\end{array}$ & $25(61.8 \pm 20.0)$ & $14(52.5 \pm 16.8)$ & $15(60.3 \pm 21.3)$ & $22(43.3 \pm 18.7)$ & $7(68.7 \pm 18.9)$ & $6(62.0 \pm 21.4)$ & 3.26 & 0.010 \\
\hline \multicolumn{9}{|c|}{ Monitoring and enforcement $($ Score $=10)$} \\
\hline $\begin{array}{l}\text { Number } \\
(\text { Mean } \pm \text { SD })\end{array}$ & $25(6.8 \pm 2.7)$ & $14(6.6 \pm 3.1)$ & $15(5.9 \pm 3.3)$ & $22(2.2 \pm 3.2)$ & $7(8.3 \pm 0.76)$ & $6(9.0 \pm 1.1)$ & 10.5 & 0.000 \\
\hline \multicolumn{9}{|c|}{ Promotion in health facilities (Score $=10)$} \\
\hline $\begin{array}{l}\text { Number } \\
(\text { Mean } \pm \text { SD })\end{array}$ & $25(8.6 \pm 3.25)$ & $14(7.9 \pm 4.2)$ & $15(8.7 \pm 3.5)$ & $22(3.3 \pm 4.5)$ & $7(8.6 \pm 3.8)$ & $6(8.7 \pm 3.2)$ & 6.11 & 0.000 \\
\hline \multicolumn{9}{|c|}{ Engagement of HWs and HSs $($ Score $=15)$} \\
\hline $\begin{array}{l}\text { Number } \\
(\text { Mean } \pm \text { SD) }\end{array}$ & $25(6.6 \pm 3.7)$ & $14(3.4 \pm 2.6)$ & $15(7.1 \pm 4.7)$ & $22(2.3 \pm 3.9)$ & $7(6.9 \pm 4.8)$ & $6(6.7 \pm 5.7)$ & 4.37 & 0.001 \\
\hline
\end{tabular}

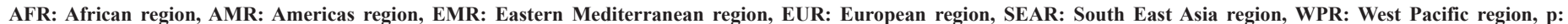
Probability, BMS: Breast-milk substitutes, EBF: Exclusive breastfeeding, HW: Health workers, HS: Health system

Table 4: Correlation of EBF and national laws that cover the Code with risk factors of CVD in the 89 countries under study

\begin{tabular}{|c|c|c|c|c|c|}
\hline Variables & $\begin{array}{c}\text { Raised } \\
\text { blood } \\
\text { sugar }^{\wedge}\end{array}$ & $\mathrm{RBP}^{\wedge}$ & $\begin{array}{c}\text { Overweight } \\
\text { (BMI>25) }\end{array}$ & $\begin{array}{c}\text { Obesity } \\
(\mathrm{BMI}>\mathbf{3 0})\end{array}$ & $\begin{array}{c}\text { Death } \\
\text { from } \\
\mathrm{NCD}^{\wedge} \wedge\end{array}$ \\
\hline EBF & $\mathrm{r}-0.004$ & $\mathrm{r}-0.25^{*}$ & $\mathrm{r}-0.3 * *$ & $\mathrm{r} 0.3 * *$ & $\mathrm{r}-0.3 * *$ \\
\hline $\begin{array}{l}\text { National } \\
\text { law } \\
\text { covering } \\
\text { code }\end{array}$ & $\mathrm{r}-0.01$ & $\mathrm{r}-0.24^{*}$ & $\mathrm{r}-0.4^{* *}$ & $\mathrm{r}-0.3^{* *}$ & $\mathrm{r}-0.4 * *$ \\
\hline Overweight & $\mathrm{r}-0.4 * *$ & $\mathrm{r}-0.01$ & - & $\mathrm{r} 0.9 * *$ & $\mathrm{r} 0.63 * *$ \\
\hline Obesity & $\mathrm{r}-0.5^{* *}$ & $\mathrm{r}-0.01$ & -r0.9 & - & $\mathrm{r} 0.56^{* *}$ \\
\hline $\begin{array}{l}\text { Monitoring } \\
\text { enforcement }\end{array}$ & $\mathrm{r} 0.1$ & $\mathrm{r}-0.3 * *$ & $\mathrm{r}-0.3 * *$ & $\mathrm{r}-0.3^{*}$ & $\mathrm{r}-0.3 * *$ \\
\hline $\begin{array}{l}\text { Promotion } \\
\text { in health } \\
\text { facilities }\end{array}$ & $\mathrm{r} 0.2$ & $\mathrm{r}-0.3 * *$ & $\mathrm{r}-0.2$ & $\mathrm{r}-0.2$ & $\mathrm{r}-0.5^{* *}$ \\
\hline $\begin{array}{l}\text { Engagement } \\
\text { of HW }\end{array}$ & $\mathrm{r} 0.1$ & $\mathrm{r}-0.4 * *$ & $\mathrm{r}-0.2$ & $\mathrm{r}-0.2$ & $\mathrm{r}-0.5^{* *}$ \\
\hline
\end{tabular}

BMI: Body mass index, EBF: Exclusive breastfeeding, NCD: Non-communicable disease, $r$ : Pearson correlation, *correlation is significant at the 0.05 level (two tailed), $* *$ correlation is significant at the 0.01 level (two tailed), $\wedge$ estimates in $2014, \wedge \wedge$ estimates in 2020. CVD: Cardiovascular disease, RBP: Raised blood pressure

Kuwait, and Egypt. A similar pattern was shown by countries in the western economies as Europe and the USA, suggesting that obesity is linked to affluence [23].

Our study showed that there were significant associations between EBF with overweight and obesity. These associations show that enactment of the Code in its entirety into the national laws can improve EBF, as well as overweight and obesity as risk factors of CVDs [24]. Moreover, violations of the Code were more prevalent in countries with high rates of overweight and obesity [8].

Mean adjusted standardized estimates of RBP were highest in the countries of EMR. RBP is an underlying cause of CVDs as well as cerebrovascular incidents increasing physical handicap, health-care costs for treatment, and resulting in premature deaths from NCDs. A longer duration of breastfeeding has been associated with a risk reduction in hypertension and myocardial infarction and T2DM [25].

Mean age-standardized estimates of RBGL is a risk factor of DM. Countries such as Kuwait and Saudi Arabia have the highest rates of DM [18]. Breastfeeding seems to exert significant protection against DM in breastfed children and their mothers; as 1-3 months of lactation reduce the cumulative incidence of DM by $80 \%$ [25].

The national legal measures for monitoring and enforcement were two-thirds of the expected score in the EMR countries but lowest in the developed countries as in European and WPRs. Breastfeeding protection through Code monitoring and enforcement is associated with the risk factors and death from CVDs [26].

Enforcement of laws is challenged by lack of clarity, knowledge and resources, the influence of cultural factors, and poverty illiteracy [27]. Civil society and media are key to monitoring the implementation of laws, but it is member states (MSs) responsibility to enact them. Civil society plays an important role in enforcing laws [28], through demanding their rights, holding their governments and duty bearers accountable, and challenge violations in criminal and civil courts. Furthermore, raising awareness of the laws and their importance in influencing breastfeeding rates and demands enforcement where there is impunity [29]. Laws regulating manufacturing, marketing, and food safety must go hand in hand with laws that address CVD risk factors including tobacco and alcohol consumption, and diet-related diseases such as laws that control the marketing of foods and beverages high in fat, sugar, or salt [30]. Laws and regulation are key tools that can support desired policy outcomes and management of inputs and processes related to breastfeeding promotion [31]. 
Most countries have adopted recommendations of EBF for 6 months. The European Society for Pediatric Gastroenterology, Hepatology and Nutrition Committee on Nutrition advises complementary feeding not to start before 4 months nor be delayed beyond 26 weeks ( 6 months), which is in contrary to the WHO recommendations of 6 months [32]. The BMS industry in Kenya is a major sponsor of HWs and systems through sponsoring their events and giving out gifts to distribute and prescribe their products to mothers. They target HWs who are the primary source of prescribing infant milk formulas. Such tactics need to be controlled by strong policies and laws.

Early introduction of supplements at birth or before 6 months interferes with the lactation reflexes and gradually diminishes the supply and effectiveness of intrinsic mechanisms for milk production [33]. They also alter intestinal microbiota and microbiomes which, in turn, predispose to the development of obesity, atherosclerosis, RBP, insulin resistance, and DM [34,35].

Death from NCD was high in the EMR but still lower than EUR, AMR, WPR, and SEAR. NCDs deaths in AFR were significantly lower than in other regions. A longer duration of breastfeeding has been associated with a risk reduction in breast cancer, ovarian cancer, endometrial cancer metabolic syndrome hypertension and myocardial infarction, and T2DM [25,36,37]. Hence, legal measures that do not cover the Code in its entirety were associated with less breastfeeding and thereby increased risk to RBP and DM mostly in HIC in EMR, EUR, and AMR.

The link between EBF and development of CVDs and NCDs may be explained by the gut microbiota. Researchers show that breastfed babies' microbiota are different than formulafed ones [38]. There is evidence indicating that gut microbiota turbulence during the vital developmental window of early infancy leads to an increased risk of chronic non-infectious diseases in later life [39]. EBF in the first 6 months of life is important in preserving the "friendly microbiota" and thereby preventing the turbulence in the microbiota that can, in turn, modulate immune responses [40]. In effect, EBF modulate immune responses later in life and predispose to CVDs and their related risk factors [40]. Since, infant milk formula promotion can undermine breastfeeding practices, hence, regulations and laws that control marketing practices can reduce the burden of CVDs and deaths from NCDs [41].

In May 2012, the $65^{\text {th }}$ WHA endorsed a Comprehensive plan on Maternal, Infant, and Young Child Nutrition that included halting the epidemic of obesity and promoting breastfeeding. Malnutrition includes overweight and obesity which are risk factors of CVDs and hypertensive disease. It begins in early infancy and can be prevented by optimal infant feeding practices $[42,43]$. The current study shows that breastfeeding protection, through the appropriate implementation of the Code, is associated with improved breastfeeding rates. The study also demonstrates an association between national laws that cover the Code of the prevention of CVDs risk factors.

However, a substantial number of countries do not have legal measures, which limited our ability to include more countries in our study. Regions with developed economies as the EUR have a large number of countries with legal measures but they were mostly characterized by having some provisions and thereby low scores. This interfered with our ability to relate to the degree to which these provisions influence the risk factors of NCDs. Furthermore, many countries in the EUR did not have breastfeeding indicators, hence, only $50 \%$ of the countries were included.

\section{CONCLUSION}

The current study shows that regulatory measures and early feeding practices are associated with the prevention of CVD risk factors and death from NCD. MSs and governmental implementing bodies globally should work on imposing laws and regulations that cover the Code in its entirety and are enforced and closely monitored. HWs and HSs need to be thoroughly aware and convinced to protect their clientele by implementing the Code and avoid commercial influence or conflicts of interest in their practice. Strategies that control overweight, obesity, and NCDs should include breastfeeding protection. Breastfeeding protection and promotion should be prioritized as the best nutrition source for infants and that early feeding with BMS may endanger the child and predispose to CVDs and death from NCDs. Adoption of stricter regulatory frameworks coupled with independent, quantitative monitoring and compliance enforcement is needed to counter the impacts of formula marketing on CVDs and NCDs globally. The hazards of formula feeding on both infant and mother health should be made known to the public and policymakers $[43,44]$. This needs to be integrated into policies not only in HSs but also in media, educational systems, industry, and legal structures for achieving health for all.

\section{REFERENCES}

1. Behairy OG, Abul-Fadl AM, Arafa OS, Abul-Fadl A, Attia MA. Influence of early feeding practices on biomarkers of cardiovascular disease risk in later life. Egypt Pediatr Assoc 2017;65:114-21.

2. World Health Organization. Preventing Chronic Disease: A Vital Investment. WHO Global Report. Geneva: World Health Organization; 2005.

3. World Health Organization. Global Status Report on Noncommunicable Disease 2014-2015. Geneva, Switzerland: World Health Organization; 2015

4. UNDP. The Human Development Concept. United States: UNDP; 2010.

5. Fewtrell M. The long term benefits of having been breastfed. Curr Pediatr 2004;14:97-103.

6. Leon-Cava N, Lutter C, Ross J, Martin L. Quantifying the Benefits of breastfeeding: A Summary of Evidence. Washington DC: Pan American Health Organization; 2004.

7. Kent G. Comparing breastfeeding and feeding with infant formula. World Nutr 2019;10:100-18.

8. World Health Organization. The International Code of Marketing of BreastMilk Substitutes-2017 Update: Frequently Asked Questions. Geneva: World Health Organization; 2017.

9. World Health Organization. International Code of Marketing of Breast-Milk Substitutes. Geneva: World Health Organization; 1981.

10. Piwoz EG, Huffman SL. The impact of marketing of breast-milk substitutes on WHO recommended breastfeeding practices. Food Nutr Bull 2015;36:373-86.

11. Parikh N, Hwang S, Ingelsson E, Benjamin EJ, Fox CS, Vasan RS, et al. Breastfeeding in infancy and adulthood cardiovascular disease risk factors. Am J Med 2009;122:656-63. 
12. Ravelli AC, van der Meulen JH, Osmond C, Barker DJ, Bleker OP. Infant feeding and adult glucose tolerance, lipid profile, blood pressure, and obesity. Arch Dis Child 2000;82:248-52.

13. Rudnicka AR, Owen CG, Strachan DP. The effect of breastfeeding on cardiorespiratory risk factors in adult life. Pediatrics 2007;119:e1107-15.

14. Fall CH, Borja JB, Osmond C, Richter L, Bhargava SK, Martorell R, et al. Infant-feeding patterns and cardiovascular risk factors in young adulthood: Data from five cohorts in low-and middle-income countries. Int J Epidemiol 2011;40:47-62.

15. Martin RM, Ness AR, Gunnell D, Emmett P, Smith GD, ALSPAC Study Team. Does breast-feeding in infancy lower blood pressure in childhood? The avon longitudinal study of parents and children (ALSPAC). Circulation 2004;16109:1259-66.

16. Nguyen B, Gale J, Nassar N, Bauman A, Joshy G, Ding D. Breastfeeding and cardiovascular disease hospitalization and mortality in parous women: Evidence from a large australian cohort study. J Am Heart Assoc 2019;8:e011056.

17. Rich-Edwards JW, Manson JE, Stampfer MJ, Manson JE, Rosner B, Hu FB, et al. Breastfeeding during infancy and the risk of cardiovascular disease in adulthood. Epidemiology 2004;15:550-6.

18. World health Organization. Status of Noncommunicable Disease by Country. Geneva, Switzerland: World health Organization; 2020.

19. World Health Organization. Marketing of Breast-Milk Substitutes: National Implementation of the International Code, Status Report 2020. Geneva: World Health Organization; 2020.

20. United Nations Children's Fund, Division of Data, Analysis, Planning and Monitoring. Global UNICEF Global Databases: Infant and Young Child Feeding: Exclusive breastfeeding, Predominant breastfeeding, New York; 2020.

21. Louis-Jacques A, Stuebe A. Long term benefits of breastfeeding. Contemp Ob Gyn 2018;63:26-33.

22. World Health Organization, NetCode Toolkit. Monitoring the Marketing of Breast-Milk Substitutes. Protocol for Periodic Assessments. Geneva, Switzerland: World Health Organization; 2017.

23. Popkin BM, Adair LS, Ng SW. Global nutrition transition and the pandemic of obesity in developing countries. Nutr Rev 2012;70:3-21.

24. Optimal Infant and Young Child Feeding for Prevention of Double-Burden of Malnutrition in EMRO: A Regional Workshop on $16^{\text {th }}$ to $17^{\text {th }}$ September 2019 in the Eastern Mediterranean Regional Office of the World Health Organization Cairo Egypt; 2019.

25. Mokaad M. Burden of cardiovascular diseases in the eastern mediterranean region, 1990-2015: Findings from the global burden of disease 2015 study. Int J Public Health 2018;63 Suppl 1:137-49.

26. Baldwin R, Cave M. Understanding Regulation: Theory, Strategy and Practice. $2^{\text {nd }}$ ed. Oxford: Oxford University Press; 2011.

27. Bingham T. The Rule of Law. London: Allen Lane; 2011.

28. Morgan B, Yeung K. An Introduction to Law and Regulation. London: Cambridge University Press; 2007.

29. Clarke D. Law, regulation and strategizing for health. In: Schmets G,
Rajan D, Kadandale S, editors. Strategizing National Health in the $21^{\text {st }}$ Century: A Handbook. Ch. 10. Geneva, Switzerland: World Health Organization; 2016.

30. Kent G. Breastfeeding: The need for law and regulation to protect the health of babies. World Nut World Public Health Nutr Assoc 2013;2:9.

31. Vaz JS, Maia MF, Neves PA, Santos TM, Vidaletti LP, Victora C. Monitoring breastfeeding indicators in high-income countries: Levels, trends and challenges. Matern Child Nutr 2021;17:e13137.

32. Guaraldi F, Salvatori G. Effect of breast and formula feeding on gut microbiota shaping in newborns. Front Cell Infect Microbiol 2012;2:94.

33. Sanz Y Santacruz A, Gauffin P. Gut microbiota in obesity and metabolic disorders. Proc Nutr Soc 2010;69:434-41.

34. Smith J, Harvey P. Chronic disease and infant nutrition: Is it significant to public health? Public Health Nutr 2011;14:279-89.

35. Sjogren YM, Tomicic S, Lundberg A, Böttcher MF, Björkstén B, SverremarkEkström E, et al. Influence of early gut microbiota on the maturation of childhood mucosal and systemic immune responses. Clin Exp Allergy 2009;39:1842-51.

36. West CE, Renz H, Jenmalm MC, Kozyrskyj AL, Allen KJ, Vuilermin P, et al. The gut microbiota and inflammatory noncommunicable diseases: Associations and potentials for gut microbiota therapies. J Allergy Clin Immunol 2015;135:3-13; quiz 14.

37. Rautava S. Early microbial contact, the breast milk microbiome and child health. J Dev Orig Health Dis 2016;7:5-14.

38. Liu Z, Roy NC, Guo Y, Jia H, Ryan L, Samuelsson L, et al. Human breast milk and infant formulas differentially modify the intestinal microbiota in human infants and host physiology in rats. J Nutr 2016;146:191-9.

39. Ma J, Li Z, Zhang W, Zhang C, Zhang Y, Mei H, et al. Comparison of gut microbiota in exclusively breast-fed and formula-fed babies: A study of 91 term infants. Sci Rep 2020;10:15792.

40. Griffin CC, Popkin BM, Spicer DS. Infant formula promotion and infant-feeding practices, Bicol region, Phillipines. Am J Public Health 1984;74:992-7.

41. World Health Organization. Implementation Guidance: Protecting, Promoting and Supporting Breastfeeding in Facilities Providing Maternity and Newborn Services-the Revised Baby-Friendly Hospital Initiative. Geneva: World Health Organization; 2018.

42. Kent G. Why make fake breastmilk? World Nutr 2020;11:2-11.

43. Rollins NC, Bhandari N, Hajeebhoy N, Horton S, Lutter CK, Martines JC, et al. Why invest, and what it will take to improve breastfeeding practices? Lancet 2016;387:491-504.

Funding: None; Conflicts of Interest: None Stated.

How to cite this article: Abul-Fadl AAM, Mourad MM, Arafa OS, Al-Jawaldeh HA. Cardiovascular disease risk factors: Role of legislations that control marketing of breastmilk substitutes. Indian J Child Health. 2021; 8(9):308-313. 